\title{
THE BOCR AND BUSINESS RULES MOTIVATION MODEL
}

\author{
Tom Feglar $^{1}$, Jason K. Levy ${ }^{2}$, Tatiana Feglar ${ }^{3}$, Tomas Feglar, jn. ${ }^{3}$ \\ ${ }^{1}$ International Consultant in Information Systems Research and Architecture, feglar@centrum.cz \\ ${ }^{2}$ University of Hawaii, Information and Computer Science Department, Pearl Citv.HI. USA. 97782, \\ jlevy@hawaii.edu \\ ${ }^{3}$ Company-Ing. Tomas Feglar, CSc., Czech Republic, feglar@centrum.cz
}

Key words: Analytic Network Process, Business Rules Motivation model, Architecture Framework, Business-Opportunities-Cost-Risk.

Summary: Benefit - Opportunity - Cost - Risk (BOCR) modeling using AHP/ANP receives large popularity in a decision making society in last few decades. Rapid increasing of enterprise information systems complexity thanks to ICT driven innovation is another symptom characterizing these decades.

Business Rules Motivation Model (BRMM) was developed by BR Group to simplify Enterprise Architects modeling business owner motivation associated primarily with a vision and desired results.

Original BRMM uses for assessment SWOT (Strength, Weakness, Opportunity, and Threat) approach that restricts Enterprise Architect especially in situation when decisions relate to ICT risks. These risks become more and more critical proportionally increasing complexity and ubiquity of information systems.

To overcome these limitations we developed new approach that allows replacement of the original SWOT assessment with BOCR.

In our paper we describe modified BRMM and the way how it can be realized using CAF (Component Architecture Framework). .

\section{ICT innovation and MCDM}

ICT innovation research concerns various aspects like information quality [7], strategy [8], organization [9], rate of technological change [10], and utility communication [13]. All these research activities let us understand only fragments of a problem if we are in a position of the enterprise architect who is responsible for a transformation of a business vision into a consistent architecture description understandable for ICT designers and builders.

Another enterprise architect's dilemma concerns decisions' situations that regularly occur in a horizon between nowadays and a vision milestone. This time horizon is usually 10 years and it is associated with enterprise strategy.

Chedia Dhaoui and Amos David propose to use two models - MDP (Model Decision Problem) and WISP (Watcher's Information Search Problem) [5]. The first model makes it possible to clarify a decisionproblem. It takes into account the decision maker problem, based mainly on two points:

- Which information on the decision- maker does one have to present so as to understand his behavior in term of stake identification and decision- making?

- How to effectively present a stake so as to understand his decision-problem and to render the decision-problem comprehensively to the watcher? 
The model WISP integrates parameters that make it possible to translate the decision-problem into a set of information retrieval problems that establish Economic Intelligence (EI) process. EI process consists of three parts:

Human Process: deals with 1 - Identification and definition of a decisional problem, 2 - Translation of the decisional problem to an information search problem;

Process that can be automated and deals with: 3 - Identification of relevant sources, 4 - Collection of relevant information, and Data processing to value added to obtain indicators;

Human Process: deals with: 6 - Interpretation of indicators, 7 - Decision.

Tzann-DwoWu proposes combines ARIS methodology (Architecture of Integrated Information System [15]) and six-sigma quality management system for production, design and development, marketing and finance [11]. Each part of this quality management system includes a set of phases. Making-decision step is one of steps in a finance part, but all previous parts and steps within these parts influence it.

Kristy Sha and others employ a fuzzy MCDM framework for a specific class of decisions concerning of development strategies of a convergence among trends encapsulated within WLAN/3G program [12]. Kristy Sha proposed Hierarchical system with 4 layers:

- $\quad$ Goal layer describes evaluating WLAN/3G strategies

- $\quad$ Aspect layer includes business, technical and environmental aspects

- $\quad$ Criteria layer includes criteria subordinated to aspects (for example business model, demand criterion and service provision are criteria subordinated to the business aspect)

- $\quad$ Strategies layer describes seven alternative strategies.

This hierarchical system supports decisions - a choice of the most optimal WLAN/3G strategy.

Ernest Forman applied Expert Choice 2000 in a context of the Federal CIO Council's "Best Practice for IT Portfolio Management” [16]. Expert Choice 2000 itself is a tool applying AHP method [19]. The CIO (Chief Information Officer) Council is a Federal Government body responsible for improvement the coordination, integration, and operation of information management and technology practices across the Federal Government. GAO and OMB explicitly included IT portfolio management as a central elements of a good IT investment management and GAO's “IT Investment Management Framework” places portfolio management at the center of its model of investment management. Finally OMB revised Circular A-130 in 2000 referring to portfolio management as a critical aspect of capital planning and specifying its use in the process.

With IT portfolio management, senior managers can evaluate a collection of ICT projects to see how they are performing, measure how well projects fit the organization's overall strategic plan and determine return of investment and risk level.

Typical AHP criteria include “Customer Impact”, “Compliance and Audit”, “Internal Rate and Return”, "Strategic Alignment”, “Target Architectural Alignment” etc. Example of alternatives can include "Thin Client Transformation Project”, “Developers Corporate Portal Enterprise Solution”, "Internet Lock Down Security”, “People Soft Financial System Upgrade”, “AS-400 Replacement” etc.

Chaanaya and Narasimhalu presented interesting modification of the SWOT (Strength, Weaknesses, Opportunities, Threats) model named HIME (Human Capital, Innovation, Market Discontinuity and Early Adopters) [25]. HIME motivation deals with lack of market and competition information rendering SWOT model ineffective in that case.

One of typical HIME features is linkage between Innovation and Market Discontinuity (IM relationships) and Innovation and Early Adopters (IE relationships).

Brief summary of ICT innovation - MCDM research:

a) All researches presented in this chapter suffer from lack of a decision context based on clearly specified architecture framework.

b) MDP/WISP models do not refer any MCDM method; without such basement final decision recommendations could be questionable. 
c) ARIS / Six sigma approach looks fine but seems to be very complex and difficult from viewpoint of customization to another enterprise that do not focuses manufacturing as the most important business process.

d) IT portfolio management using EC 2000 is very good approach targeting to the ICT project budgeting preferences and modeling resource allocation scenarios. From enterprise architect's standpoint this approach requires involvement of experienced architect who helps other stakeholders overcoming a gap between AHP alternatives (ICT projects) and AHP criteria (that combine business as well as technological aspects).

e) SWOT / HIME approach captures important relationships between ICT innovation, Market Discontinuity and Early adopters. This approach supports primarily a snapshot of a company's health; it is not suitable for enterprise strategy until it would be integrated with ICT life cycle history.

\section{Decision Analysis and AHP/ANP form Enterprise Architect's Perspective}

More then one decade we may observe increasing significance of an ICT architect's profession. It becomes more complex and requires multidisciplinary skill similarly to its older brother - building (constructing) architect. Enterprise Architect (EA) is understood as the most experienced architect who is able to coordinate solution and IT architects.

EA must specify what reference architecture framework (one or more) will be applied as a basement for all ICT systems developed, customized, deployed and operated within an enterprise. Reference architecture frameworks choice must consider a lot of factors. Some frameworks are tightly coupled with business domain (Military and C4ISR framework [26]), with ERP solution (SAP and ARIS [15]). Others frameworks can be applied interchangeably and effectively to various types of enterprises (like Zachman [27] and TOGAF [28]). Thomas Zwahr and Matthias Finger presented a holistic framework for eGovernance model that combines three frameworks - Zachman, TOGAF and C4ISR (the last one precisely describe particular elementary architecture products that are created by EA and then used for more complex architectural constructs [29]).

Architecture frameworks offer very good basement for decision analysis and decision context synthesis. Surprisingly only very few papers were published about this topic [17,30,31]. Guy Documents developed a GRAI-grid as a part of a methodology for E-Business solution. Using these grid in combination with Decision nodes one can create very consistent decision context with clear linkages to other parts of GRAI framework (30, 31]. GRAI decision nodes do not apply any popular MCDM method like AHP, MAVT, MAUT eventually others [24]. Component Architecture Framework (CAF) approach was designed in accordance with AHP / ANP decision context needs [17]; decision space has linkages to the particular project enterprise entities (PEE) that describe system life cycle from architect's perspective (figure 1). ICT innovation can activate two kinds of enterprise changes:

- First change allows creation of a new information system that was not technologically solvable before ICT innovation appeared or benefit / cost ratio for particular workflows was so low that information system for those workflows was not effective.

- Second change activates large changes in already operational information system. Typical example is a replacement a set of small bespoke applications with more complex solution based on more powerful application servers like Biztalk (Microsoft), SAP Netweaver, Oracle Business Suite or others.

Both kinds of enterprise changes must be carefully planned. Schedules include milestones in which any kind of decision has to be done. A lot of aspects influence such decisions and it is very important to replace intuitive decisions (mostly preferred technological aspects) with formal decision support models. CAF has chosen ADP for this purpose primarily on the base of successful testing and application of AHP [32]. Not all enterprise changes require ANP based decisions. We focus our attention on strategic and tactical level. These two levels influence budgeting ( for example "Best Practice for IT Portfolio Management" is one of areas that could be solved by ANP; Decision Context (DC) could be established directly by Enterprise Architect within Zachman architecture framework. 


\section{Decision Analysis and AHP/ANP form System Engineer's Perspective}

Proportionally increasing complexity of enterprises more and more attention is given to engineering processes - how clearly are specified, how well are managed and how they interact each other.

Figure 2 depicts five system engineering (SE) processes that have critical impact to the IT budgeting and IT security from a perspective capital planning and investment control (CPIC) process. Architecture Design Process, Risk Management Process and Security Project management (a part of Information Management Process) directly manage each information (communication) system in its development or changeable status (Project Enterprise Entity is relevant term used by architect). Information Management Process also supervises information (communication) system during its operational phase.

Strategic (Tactical) Decision-Making Process directly interacts with ADP and RMP.

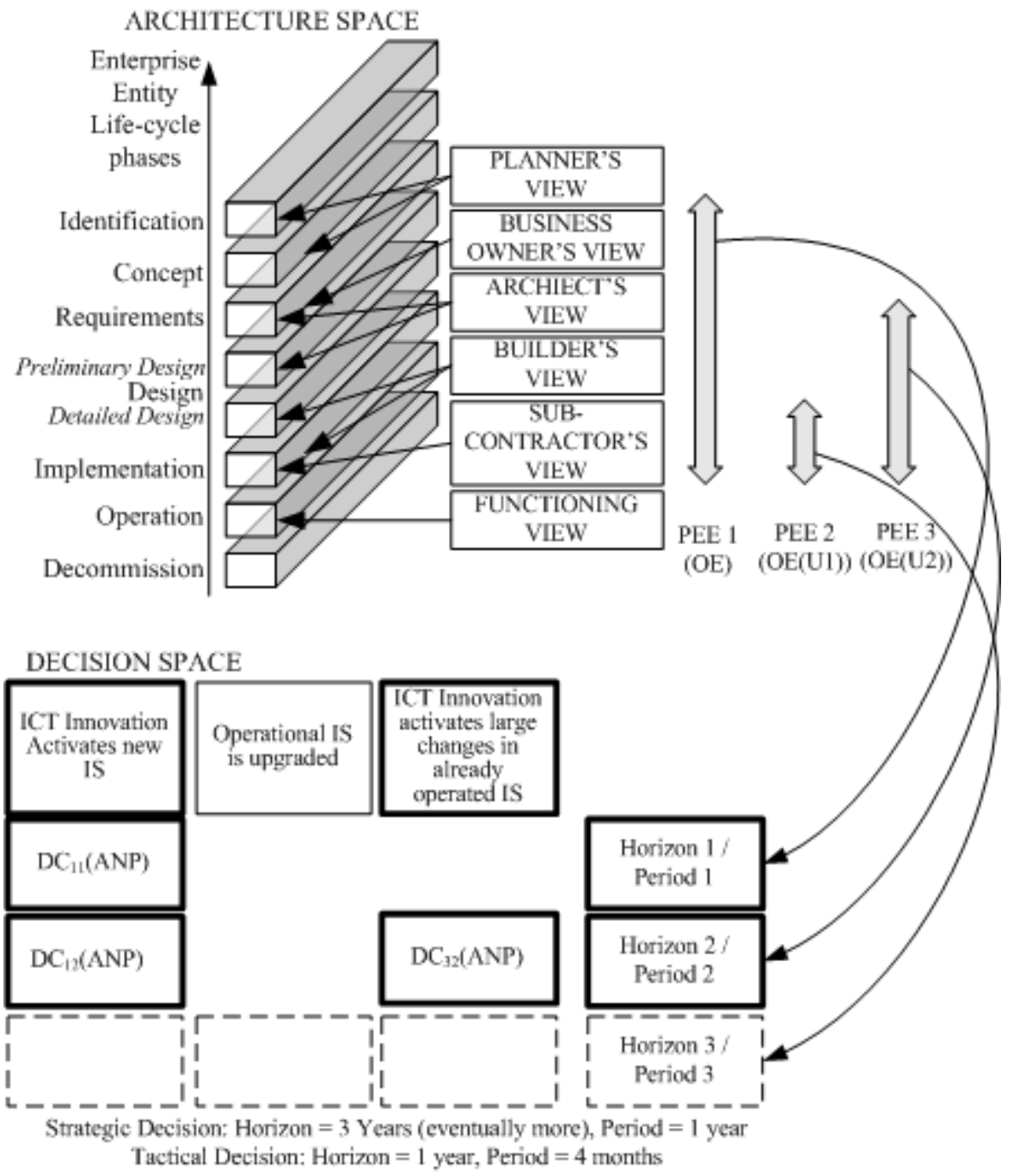

Figure 1. ICT Innovation requires synchronization between information system life cycle and decision space.

SE Concept in the figure 2 is sporadically applied in practice; it implies various negative impacts (for example larger budget is necessary when one solves IT independently on IT security, significant architectural or risk decisions are made separately and sometimes intuitively). 


\section{BRMM and BOCR}

Business rules are a common asset in every company. Business rules are the very essence of a business. They define the terms and state the core business policies. They control or influence business behavior. They state what is possible and desirable in running a business - and what is not. One can increase agility of an organization by a better management and enforcement of this valuable business asset.

The Business Rules Approach (BRA) is a combination of existing and new techniques and technologies in order to identify the knowledge required to run a business, to document this knowledge, to reason about it, to make it operational in a consistent way, to systematically adapt it to ever changing market forces and to automate this knowledge as far as possible. The Business Rules Approach is based on the Zachman Framework to ensure a holistic enterprise view.

\subsection{The Business Rule Motivation Model (BRMM)}

The BRMM has been established by Business Rule Group to simplify business planning, especially in parts that relate to engineering business processes that include automated components [23].

The BRMM consists of two major areas [Figure 3):

- $\quad$ The first is the Ends and Means of business plans. Among the Ends are things the enterprise wishes to achieve - for example, Goals and Objectives. Among the Means are things the enterprise will employ to achieve those Ends - for example, Strategies, Tactics, Policies, and Business Rules.

- The second is the Influence that shapes the elements of the business plans, and the Assessment made about the impacts of such Influences on Ends and Means (i.e. Strengths, Weaknesses, Opportunities, and Threats (SWOT)). In many cases influences assessment is not enough business owners need to make a decision. Assessment and Decision has to be tightly coupled each other. ANP is exactly what we need for this coupling - it gives us a system of control criteria that we use to assess influence. Doing this, ANP at the same time allows us transformation from primarily analytical SWOT space to primarily decision-making BOCR (Benefit, Opportunity, Cost, and Risk)) space [20, 22].

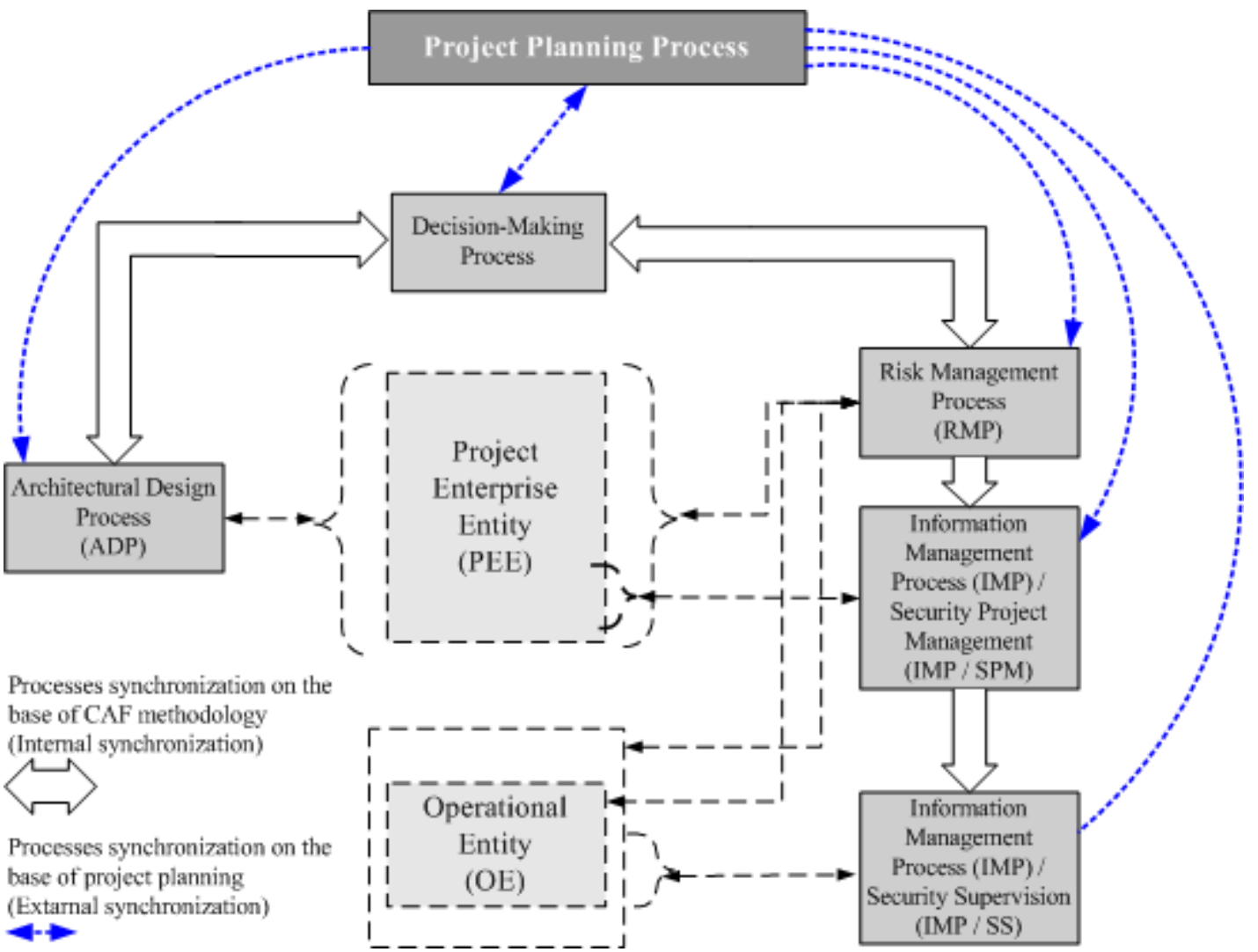

Figure 2. Five SE processes those are responsible for IT budgeting and IT Security Integration into CPIC Process 


\subsection{Business, Opportunities, Costs, and Risk (BOCR)}

Currently used BRMM does not apply BOCR; it uses purely SWOT. At the same time there is no obstacle for BOCR encapsulation into BRMM - as additional module or instead SWOT. Figure 3 depicts the second possibility.

BOCR itself is very strong method theoretically $[20,22]$ as well as practically (as Super Decision software [18]). BRMM Encapsulation means that we must establish functional linkages among BOCR module and other BRMM modules and sub-modules.

\section{a) End Module}

An End is a statement about what the business seeks to accomplish. In describing Ends, it is useful to document who defined the End and at what point in time, so that an audit trail exists for future reference. End concepts can be arranged in a hierarchy (figure 3). An End may be either a Vision, or some Desired Result (a Goal or an Objective). The essence is that these are types of things, in varying detail that the enterprise is trying to accomplish.

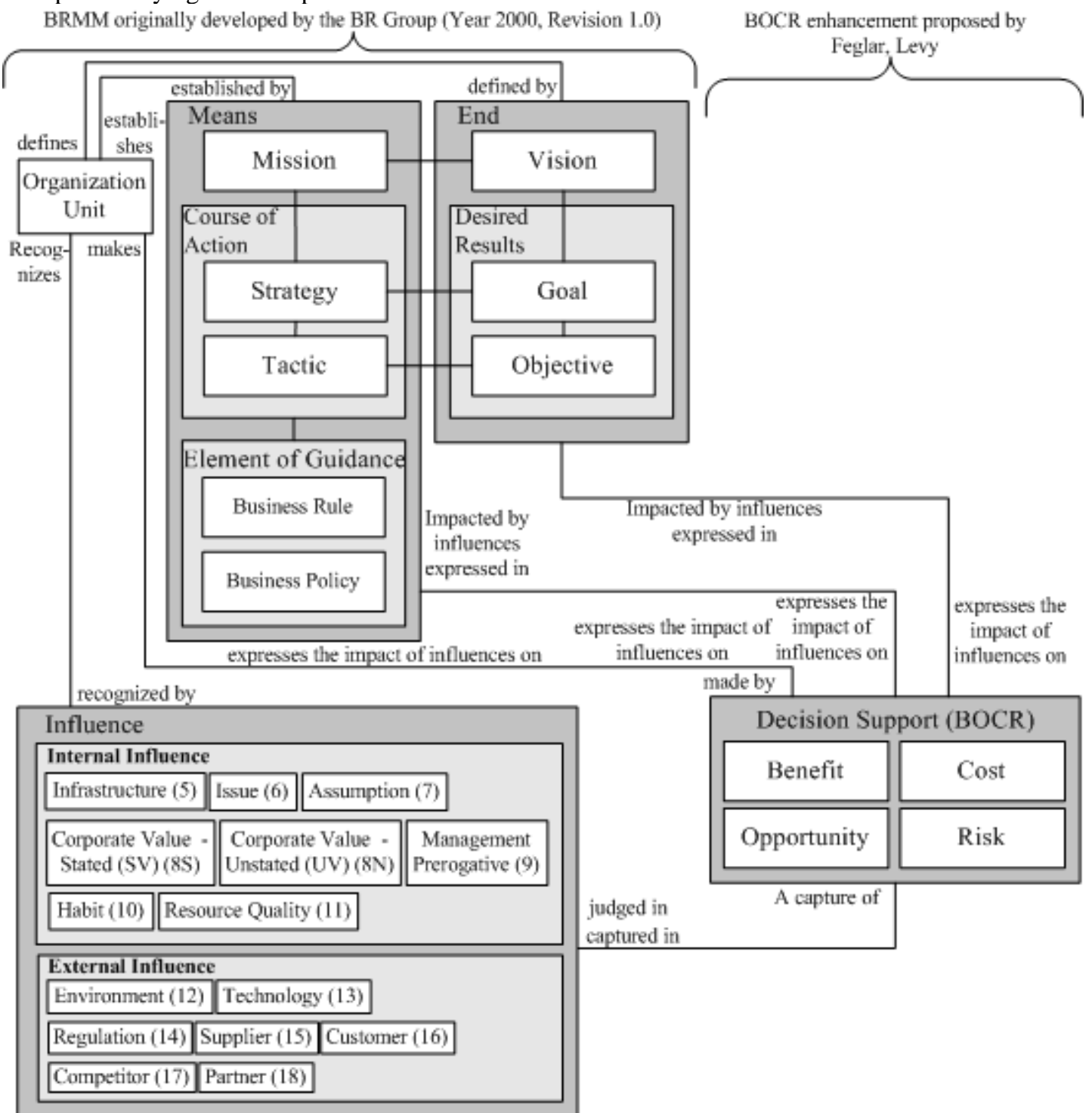

Figure 3. BRMM with BOCR functionality

\section{b) Means Module}

A Means represent any device, capability, regime, technique, restriction, agency, instrument, or method that may be called upon, activated, or enforced to achieve Ends. In describing Means, it is useful to 
document who established the Means and at what point in time, so that an audit trail exists for future reference.

Means concepts can be arranged in a hierarchy (figure 3). A Means may be either a Mission, a Course of Action (a Strategy or Tactics), or an Element of Guidance (Business Policy or Business Rule).

A Mission indicates the ongoing operational activity of the enterprise. The Mission describes what the business is or will be doing on day-to-day basis. A Mission makes a Vision operative - that is, it indicates the ongoing activity that makes the Vision a reality. A Mission is planned by Means of Strategies.

A Course of Action is an approach or plan for configuring some aspects of the enterprise involving things, processes, locations, people, timing, or motivation, undertaken to achieve Desired Results. Course of Action includes Strategy and Tactics.

A Strategy is one component of the plan for the Mission. A Strategy represents the essential Course of Action to achieve Ends - Goals in particular.

A Tactic is a Course of Action that represents part of detailing of Strategies. A Tactic implements Strategies.

\section{c) Influence Module}

Influences allow us identification and understanding elements that have to be considered every time when our plans suppose making a decision.

An Influence is the act, process, or power of producing an effect without apparent execution of tangible force or direct exercise of command, and often with unpredictable effort or event that can seriously impact operational enterprise if it remains out of control. On the other site, wise versa involvement of influences into decision process can significantly improve final decision; winner alternative chosen on the base of criteria that consider also influences are more stabile and closer to the reality especially in the case of strategic decisions.

There are two general categories of influences (Figure 3):

- Internal influence

- External Influence

\section{C1) Internal Influence}

Internal influences are those from within an enterprise that cam impact its employment of Means or achievements of Ends. Internal influences include:

- Infrastructure: The basis underlying framework or features of a system

- Issue: A point in question or a matter that is in dispute as between contending partners

- Assumption: Something that is taken for granted or without proof.

- Corporate Value: An ideal, custom, or institution that an enterprise promotes or agrees (either positive or negative)

- Stated Value (SV): explicitly set forth and declared as fact

- Unstated Value (UV): not explicitly declared but understood by some or all of the people in an enterprise

- Management Prerogative: A right or privilege exercised by virtue of ownership or position in an enterprise.

- Habit: A customary practice or use.

- Resource Quality: The quality of resource available for carrying out the business of an enterprise.

\section{C2) External Influence}

External influences are those outside an enterprise's organizational boundaries that can impact its employment that cam impact its employment of Means or achievements of Ends. External influences include:

- Environment: The aggregate of surrounding conditions or influences affecting the exercise (or is associated with the subject enterprise to share risks and profit) because this is mutually beneficial. 
- Technology: An influence that is caused by technology - that is, the things that technology requires or will not allow to be done.

- Regulation: A rule or order prescribed by an authority such as a government body or the management of an enterprise

- Supplier: A role played by an individual or enterprise that can furnish or provide products or services to the subject enterprise

- Customer: A role played by an individual or enterprise that is a prospect, or has order, received, or paid for products or services form the subject of an enterprise.

- Competitor: A rival enterprise in a struggle for advantage over the subject enterprise.

- Partner: An enterprise that shares risks and profit with the subject enterprise (or is associated with the subject enterprise to share risks and profit) because this is mutually beneficial.

\subsection{BRMM / BOCR Functional Model}

CAF allows construction BRMM / BOCR functional model in accordance with principles depicted in the figure 4 .

Zachman framework plays two roles:

a) It is a decision context for decision-making process. One of its cells (combination of business perspective and motivation aspect) includes BRMM and within it ANP model.

b) It is a target environment for implementation of results of a decision.

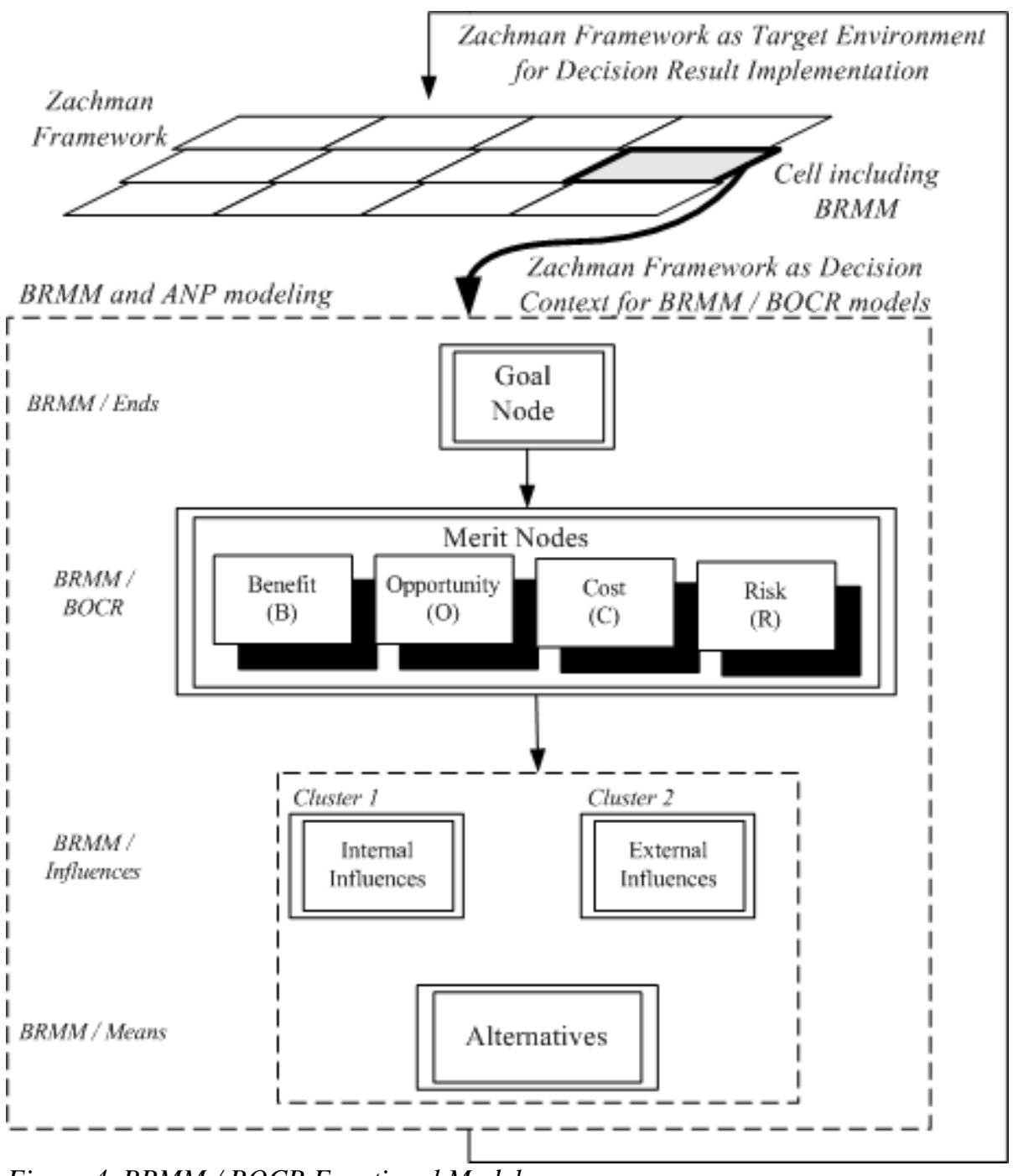

Figure 4. BRMM / BOCR Functional Model 


\section{Conclusion}

Our paper explains the most characteristic features allowing enterprise architect smart integration of decision-making process into architecture framework. It brings positive outcomes for both - architects and decision makers.

Decision maker has far simple situation at the beginning of modeling because Enteprise Architect could deliver decision context. Enterprise Architect can explain much better decision results and eventually convert them into architecture framework. .

\section{References}

[1] SCI'2005, The 8th World Multi-Conference on Systemics, Cybernetics and Informatics, Proceedings. July 18-21, 2004 Orlando, Florida, USA

[2] IEEE 2004, International Engineering Management Conference, 18-21 October 2004, SINGAPORE

[3] PISTA 2004, International Conference on Politics and Information Systems: Technologies and Applications, July 2004, Orlando, Florida, USA

[4] MCDM 2004, $17^{\text {th }}$ International Conference Multiple Criteria Decision Making, August 6-11 2004, Whistler B.C. Canada.

[5] SCI2004/04: The use of Economic Intelligence process and information and communication technologies to enhance decision process in an enterprise. Chedia DHAOUI, Amos DAVID [2]

[6] PISTA 2004/01: Enhancing the E-Governance Model: Enterprise Architecture as a Potential Methodology to Build a Holistic Framework, Zwahr, Thomas and Finger, Matthias

[7] PISTA 2004/02: E-Government Information Quality (e-GIQ) Framework, Chutimaskul, Wichian; Wangpipatwong, Sivaporn (Thailand), [4].

[8] IEEE 2004/05: Evaluating Development Strategies for Taiwans iB3G Industry: a Fuzzy MCDM Approach 258, K. H. C. K. Sha, C. Y. Hung, B. S. P. Lin, [3]

[9] IEEE 2004/01: The Seven Habits of Highly Effective Programs, Practices you need to change your organization with information technology, Mark Crowne

[10] PISTA 2004/05: Networking Technologies and the Rate of Technological Change, Mitchell, Charles L. [4]

[11] SCI2004/06: Six sigma real-time decision making management system for integrating production, design and development, marketing and finance management in Taiwan, Tzann-Dwo Wu [2]

[12] MCDM2004/1: Establishing Strategies for Development of an Emerging Integrated Network Industry: A Fuzzy MCDM Approach, Sha,K.H.K., Hung,C.Y., Tzeng,G.H.,

[13] SCI2004. Bauman,R.: "Private WAN Infrastructure for today's Utility Communication"

[14] Feglar,T., Levy,J.K.: "Dynamic Analytic Network Process: Improving Decision Support for Information and Communication Technology”, ISAHP 2005.

[15] Scheer,A.W.: “ARIS - Business Process Framework:, Springer, ISBN 3-540-65834-3.

[16] http://www.expertchoice.com/epfa/default.htm: "IT Portfolio Management with Expert Choice.

[17] Feglar,T.: “AHP/ANP Usage for a Cooperation between IT Architect and Decision Maker”, [4]

[18] Saaty,Rozann.W.: "Decision Making in Complex Environment”, Super Decisions Software for Decision Making with Dependency and Feedback.

[19] Saaty,T.L.: "The Analytic Hierarchy Process - Fundamentals of Decision Making and Priority Theory”, RWS Publications, Pittsburg, ISBN 0-9620317-6-3.

[20] Saaty,T.L.: "The Analytic Network Process - Decision Making With Dependence and Feedback", RWS Publications, Pittsburgh, ISBN 0-9620317-9-8.

[21] Saaty,T.L.:”Time Dependent Decision - Making: Dynamic Priorities in AHP / ANP”, ISAHP 2003 CD.

[22] Saaty, T.L..: “The Analytic Network Process: Dependence and Feedback in Decision Making (Part1) Theory and Validation Examples"”, [4]

[23] The Business Rules Group: “Organizing Business Plans - The Standard Model for Business Rules Motivation”, November 15, 2000, 47 p., http://www.BRCommunity.com

[24] Hamalainen,R.P.: "Reversing the Perspective on the Applications of Decision Analysis", Decision Analysis, Volume 1, No.1, March 2004.pp. 29 - 35.

[25] Chaanakya,A.D., Narasimhalu,A.D.: “An Entrepreneur's Dilemma: To SWOT or Not to SWOT”, [2], pp. $67-69$. 
[26] Wagenhals,L.W., Levis,A.H., Haider,S.: “Advances in C4ISR Architectures. Object Orientation for Architecting: A Candidate process".

[27] Zachman,J.: "A framework for information systems architecture”, IBM System Journal, Vol. 26, No. 3, 1999, pp. $454-470$.

[28] The Open Group, “TOGAF as an Enterprise Architecture Framework”, 2003.

[29] Zwahr,T., Finger,M.: "Enhancing the e-Governance model: Enterprise Architecture as a potential methodology to build a holistic framework".

[30] Doumeingts,G., Vallespir,B., Zanettin,M., Chen,D.: “GIM, GRAI Integrated Methodology, A Methodology for Designing CIM systems, Version 1, LAP/GRAI, University Bourdeaux, France, 1992.

[31] Doumeingts,G.: "Th Application of GRAI Approach to the Service", IFIP / IFAC task Force Detroid Meeting, Detroid, 1997.

[32] DoD: "Personnel Information Management System - A proposal of the Solution”, February, 2004. 